\title{
Monitoring Grassland Tourist Season of Inner Mongolia, China Using Remote Sensing Data
}

\author{
Quansheng Ge, ${ }^{1}$ Xi Yang, ${ }^{2}$ Zhi Qiao, ${ }^{3}$ Haolong Liu, ${ }^{1}$ and Jun Liu ${ }^{1,2,4}$ \\ ${ }^{1}$ Institute of Geographic Sciences and Natural Resources Research, Chinese Academy of Sciences, A11 Datun Road, \\ Chaoyang District, Beijing 100101, China \\ ${ }^{2}$ College of Geography and Tourism, Chongqing Normal University, No. 12 Tianchen Road, Shapingba District, \\ Chongqing 400047, China \\ ${ }^{3}$ State Key Laboratory of Water Environment Simulation, School of Environment, Beijing Normal University, \\ Xinjiekouwai Street, Beijing 100875, China \\ ${ }^{4}$ Tourism School, Sichuan University, Chengdu 610064, China
}

Correspondence should be addressed to Jun Liu; liujun_igsnrr@126.com

Received 12 February 2014; Accepted 24 March 2014; Published 10 April 2014

Academic Editor: Dong Jiang

Copyright (C) 2014 Quansheng Ge et al. This is an open access article distributed under the Creative Commons Attribution License, which permits unrestricted use, distribution, and reproduction in any medium, provided the original work is properly cited.

\begin{abstract}
Phenology-driven events, such as spring wildflower displays or fall tree colour, are generally appreciated by tourists for centuries around the world. Monitoring when tourist seasons occur using satellite data has been an area of growing research interest in recent decades. In this paper, a valid methodology for detecting the grassland tourist season using remote sensing data was presented. On average, the beginning, the best, and the end of grassland tourist season of Inner Mongolia, China, occur in late June ( \pm 30 days), early July ( \pm 30 days), and late July ( \pm 50 days), respectively. In south region, the grassland tourist season appeared relatively late. The length of the grassland tourist season is about 90 days with strong spatial trend. South areas exhibit longer tourist season.
\end{abstract}

\section{Introduction}

Phenology-driven events, such as spring wildflower displays or fall tree colour, make some destinations become particularly attractive [1]. During the spring, cherry blossom viewing kicks off the busy tourist season around the world. In Japan, holding flower-viewing parties is a centuries-old practice under blooming cherry trees [2]. The National Cherry Blossom Festival 2013 in Washington DC attracted about 100,000 tourists from around the world. In China, the beautiful and elegant peach blossoms have inspired generations of spectators. In Europe, Netherland's tulips prove huge draw for tourists.

Monitoring the timing of plant life cycle events is an area of science with many practical applications for tourism sector, because the timings determine when tourist season begins and ends. Phenology then can serve as a predictor to inform the public on when certain events take place. Based on phenological information, tourism sector will be better able to prepare themselves for peak and/or off-season. Tourists would adjust their vacation to nature reserves to the timing of certain life cycle events. As plant phenophases are sensitive to climate change, variations in the timing of vegetation phases are key components to identify and evaluate the effects of climatic change on tourism industry [3].

The timings of plant life cycle events have been detected by ground observations for centuries [4]. However, field phenology observations are difficult to upscale to large spatial scale and labor intensive. Satellite-based measure could provide the potential to extrapolate from species-level observations to regional variations of phenological patterns.

Grasslands play a vital role in tourism sector because grasslands provide recreation and tourism services include horse riding, safari tours, and hunting. At the country level, China takes the third place after Australia and Russia in grassland area. Nearly $42 \%$ of China is natural grassland, comprised of a total of 393 million hectares. 


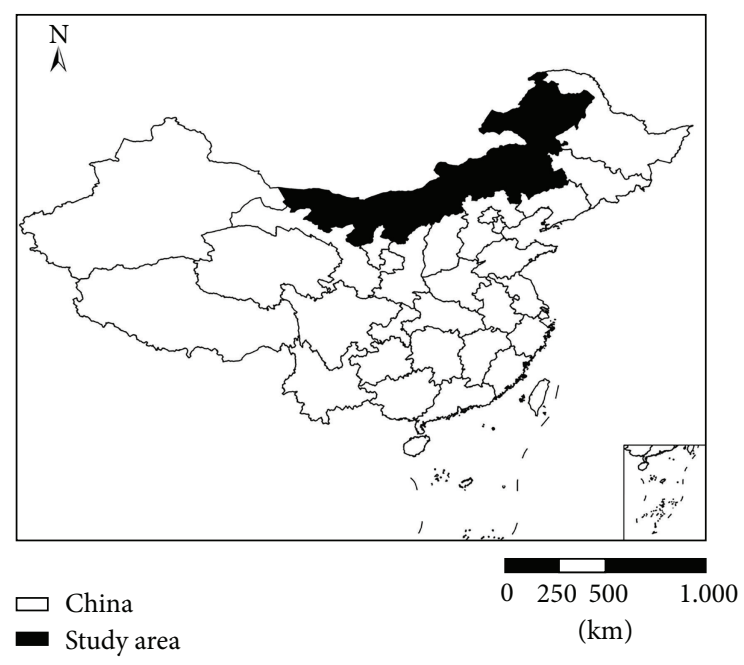

Figure 1: The location of study area.

In this paper, we present a satellite-based method to monitor the start and end of the tourist season for grassland in North China. This work can be of crucial importance to better understand how grassland responds to climatic change and, consequently, to design effective adaptation and management policy for tourism sector.

\section{Study Area}

The Inner Mongolia Autonomous Region is situated between longitude $97^{\prime \prime} 12^{\prime \prime} \mathrm{E}-126^{\prime \prime} 04^{\prime \prime} \mathrm{E}$ and latitude $37^{\prime \prime} 24^{\prime \prime} \mathrm{N}-$ $53^{\prime \prime} 23^{\prime \prime} \mathrm{N}$, with an area of 1.183 million $\mathrm{km}^{2}$ taking up $1 / 8$ of that of China (Figure 1). Situated on the climatic boundary between the humid monsoon region and the inland arid area, Inner Mongolia is a region of extreme contrasts in climate. The annual mean temperature is about $0-3^{\circ} \mathrm{C}$. July is on average the warmest month, with an average temperature of $15-25^{\circ} \mathrm{C}$. The average sunshine totals throughout the year are more than 2700 hours. Average annual precipitation exhibits a sharp gradient, from $600 \mathrm{~mm}$ in the east to $<100 \mathrm{~mm}$ in the west [5].

Inner Mongolia is one of the most representative grassland regions of China [6]. The area of grassland accounts for 27 percent of the nation's total. With the most representative grassland in China, the region is an appealing destination for grassland tourism in China as well as a sign of ecological tourism. Grassland related tourism has become a vital sector of Inner Mongolia. The number of tourists increased 16.8 percent each year and revenues increased 28.6 percent from 2006 to 2010 . By 2015, tourism sector is predicted to generate a direct contribution to GDP of $\$ 25$ billion or 8 percent of GDP.

\section{Material and Methodology}

3.1. Material. MOD13 A2 8-day NDVI and NDVI Quality Assurance products from Terra's Moderate Resolution Imaging Spectroradiometer (MODIS) were obtained from the US

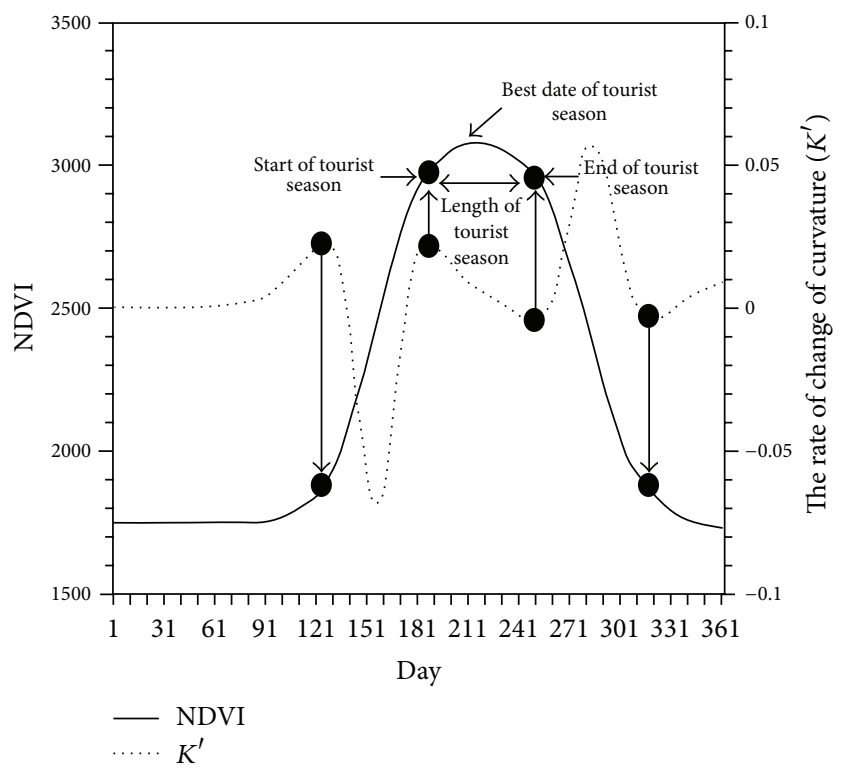

FIgURE 2: The reconstructed NDVI time series and the dates of tourist season.

Geological Survey consisting of a total of 46 images with a spatial resolution of $1 \mathrm{~km}$. The dataset includes 1 year (January 1,2008 , to December 31,2008), and it is well suited to detect grassland tourist season at the scale of the landscape.

The NDVI is calculated by

$$
\mathrm{NDVI}=\frac{(\mathrm{NIR}-\mathrm{VIS})}{(\mathrm{NIR}+\mathrm{VIS})},
$$

where VIS and NIR are the spectral reflectance measurements acquired in the visible (red) and near-infrared regions, respectively.

3.2. Methodology. Grassland tourist seasons define the period of time when grassland conditions are suitable for tourism activities. Zhang et al. [7] defined maturity as the date when vegetation green leaf area reaches a maximum. The senescence is decided to occur when green leaf area begins to rapidly decrease. Figure 2 illustrates how the onset, best date, the end, and thus length of the tourist season are determined based on the satellite derived NDVI. The bottom axis represents time (in days) and the side axis represents reflectance values.

Function (2) is used to model the annual change in satellite derived vegetation index data for a single growth or senescence cycle:

$$
y(t)=\frac{c}{1+e^{a+b t}}+d,
$$

where $y(t)$ is the NDVI value at time $t, t$ is time in days, $a$ and $b$ are fitting parameters, $d$ is the initial background NDVI value, and $c+d$ is the maximum NDVI value. Least square fitting was used to determine the fitting parameters $a$ and $b$.

The onset of transition dates corresponds to the times at which the second derivative gets from positive to negative 


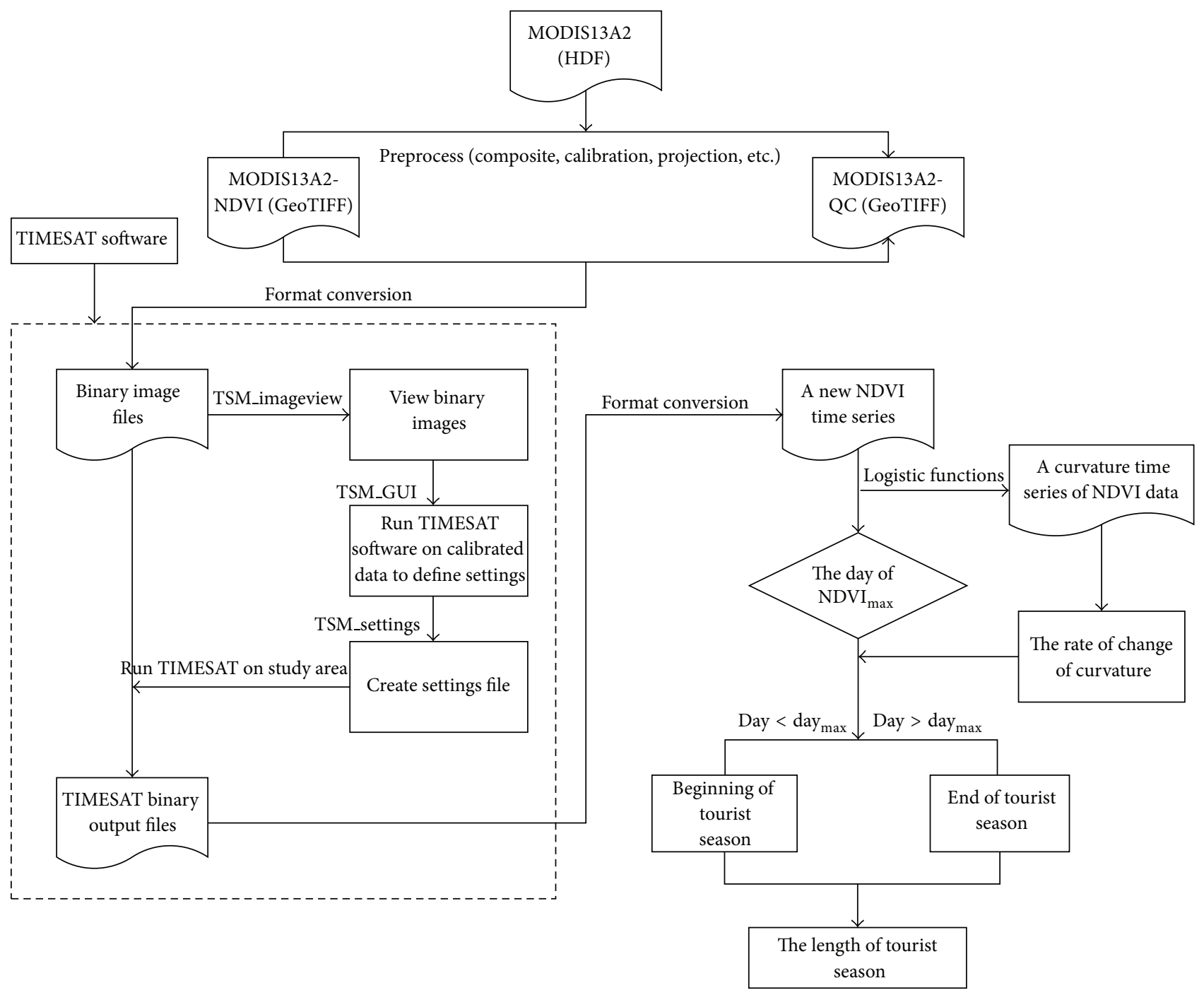

FIGURE 3: Flowchart of grassland tourist season monitoring process.

values. The curvature $K$ for (2) at time $t$ can be calculated by [7]

$$
K=\frac{d_{a}}{d_{s}}=-\frac{b^{2} c z(1-z)(1+z)^{3}}{\left[(1+z)^{4}+(b c z)^{2}\right]^{3 / 2}},
$$

where $z=e^{a+b t}, a$ is the angle of the unit tangent vector at time $t$ along a differentiable curve, and $s$ is the unit length of the curve. The rate of the change in the curvature of the fitted logistic models is used to determine the onset of transition dates (Figure 2). The following is used to compute the rate of change of curvature:

$$
\begin{gathered}
K^{\prime}=b^{3} c z\left\{\frac{3 z(1-z)(1+z)^{3}\left[2(1+z)^{3}+b^{2} c^{2} z\right]}{\left[(1+z)^{4}+(b c z)^{2}\right]^{5 / 2}}\right. \\
\left.-\frac{(1+z)^{2}\left(1+2 z-5 z^{2}\right)}{\left[(1+z)^{4}+(b c z)^{2}\right]^{3 / 2}}\right\} .
\end{gathered}
$$

Figure 3 is the detailed flowchart of grassland tourist season monitoring process. To eliminate the abnormal value, that is, cloud and snow, a series of preprocessing steps were performed to smooth satellite data products using TIMESAT software. Then, the VI data could be fit to logistic functions described by (2). For the corrected dataset, we identified the tourist seasons for grassland by Arc Macro Language (AML) programming using the above methods.

\section{Results}

4.1. The Onset of Grassland Tourist Season. Remote sensing measures of tourist season showed a high degree of spatial variability over the study period. In most regions, grassland tourist season of Inner Mongolia begins in late June $( \pm 30$ days). The earliest date was May 30th. The latest date was August Third. Note that north areas exhibit earlier onset of tourist season (Figure 4). 


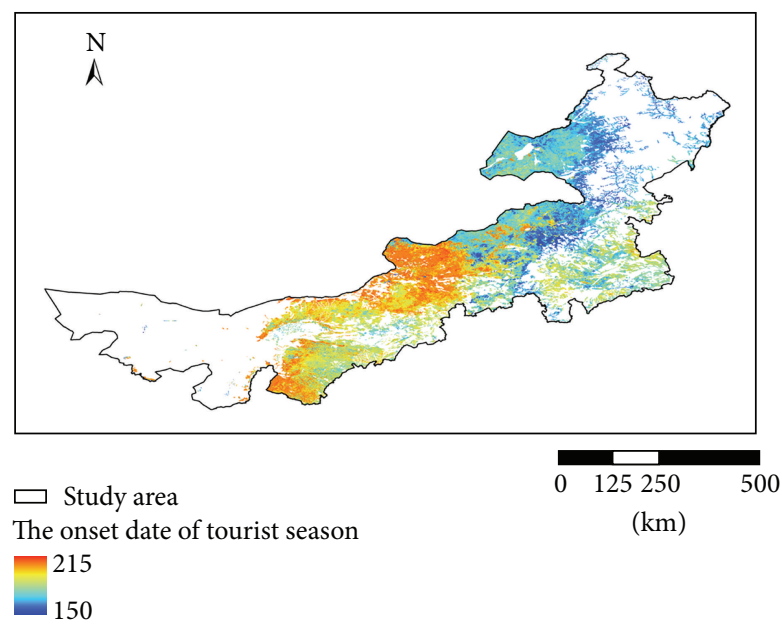

FIgURE 4: The onset of grassland tourist season.

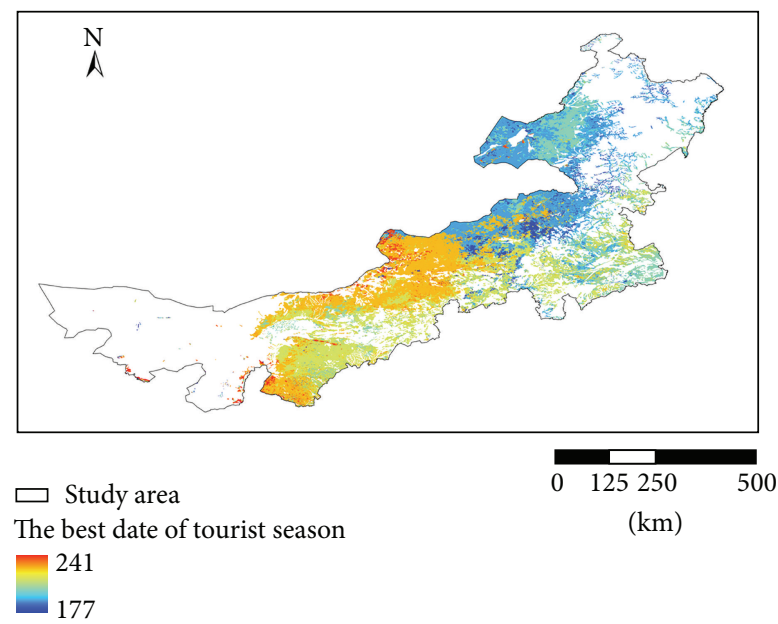

Figure 5: The best date of grassland tourist season.

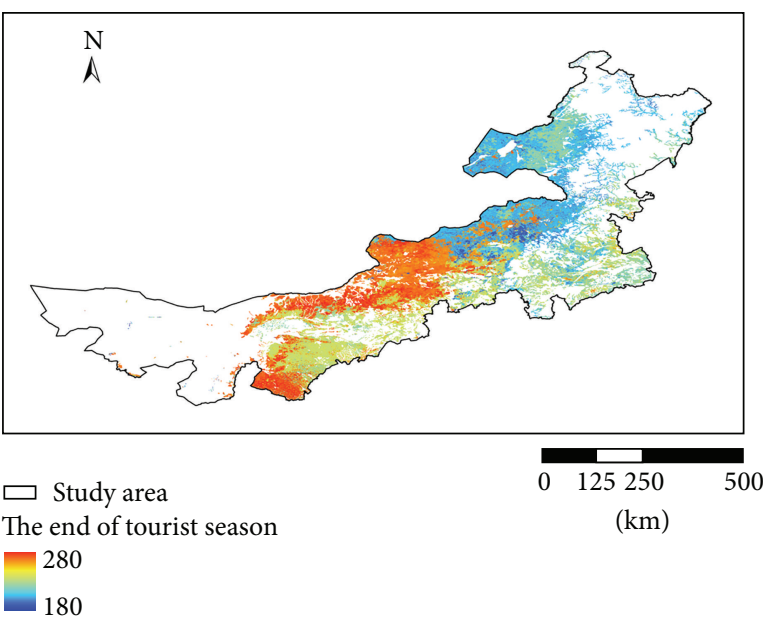

Figure 6: The end of grassland tourist season.

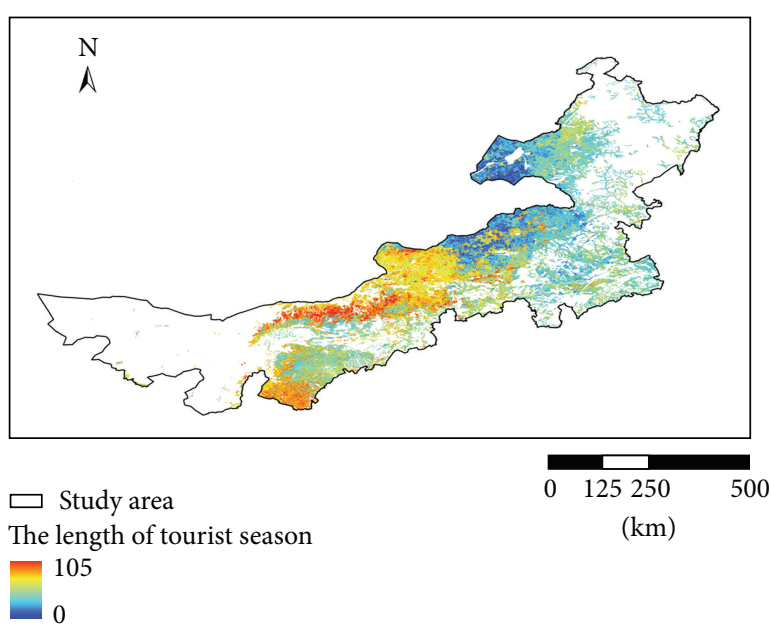

Figure 7: The length of grassland tourist season.

4.2. The Best Date of Grassland Tourist Season. The average best date of grassland tourist season in Inner Mongolia started approximately in early July ( \pm 30 days), though the initiation period ranged over more than a 30-day period, beginning in southerly latitudes in late August and advancing northward. The earliest date was June 26th. The latest date was August 29th. Pronounced spatial variability in the timing of best tourist season is particularly evident (Figure 5).

4.3. The End of Grassland Tourist Season. The average end of grassland tourist season started in late July ( \pm 50 days). The earliest date was June 30th. The latest date was October 7 th. In south region, the end of grassland tourist season appeared relatively late (Figure 6).

4.4. The Length of Grassland Tourist Season. Satellite-based measurements of the length of grassland tourist season for Inner Mongolia spanned a period of approximately 3 months from late June to late September with strong spatial trend. South areas exhibit longer tourist season (Figure 7).

\section{Conclusion and Discussion}

A major focus of this research is to present a valid methodology for detecting the grassland tourist season using remote sensing data. On average, the beginning, the best, and the end of grassland tourist season of Inner Mongolia occur in late June, early July, and late July, respectively. The length of the grassland tourist season is about 90 days. The grassland tourist season shows strong spatial variation that might depend on grass species.

Our results indicate that tourist season for grassland can be effectively measured by space-borne radar remote sensing, providing a potentially flexible, repeatable, and realistic way to monitor regional tourist timings. These timings appear to have a major influence on regional patterns of tourist flows. This parameter has implications for tourists and the tourism industry with reference to the timing of trips and their promotion. To improve accuracy, sufficient comparison 
between land surface phenology and in situ values is an essential issue.

\section{Conflict of Interests}

The authors have declared that no conflict of interests exists.

\section{Acknowledgments}

This study was supported by the Key Project of the National Natural Science Foundation of China (NSFC, no. 41030101) and the National Basic Research Program of China (973 Program no. 2010CB950100).

\section{References}

[1] Q. Ge, J. Dai, J. Liu, S. Zhong, and H. Liu, "The effect of climate change on the fall foliage vacation in China," Tourism Management, vol. 38, pp. 80-84, 2013.

[2] Brooklyn Botanic Garden, Mizue Sawano: The Art of the Cherry Tree, Brooklyn Botanic Garden, 2006.

[3] E. Ivits, M. Cherlet, G. Tóth et al., "Combining satellite derived phenology with climate data for climate change impact assessment," Global and Planetary Change, vol. 88-89, pp. 85-97, 2012.

[4] K. Zhu and M. Wan, Productive Science-Phenology, Public Science, 1963.

[5] G. Zhang, Y. Kang, G. Han, and K. Sakurai, "Effect of climate change over the past half century on the distribution, extent and NPP of ecosystems of Inner Mongolia," Global Change Biology, vol. 17, no. 1, pp. 377-389, 2011.

[6] J. Liu, X. Yang, H. Liu, and Z. Qiao, "Algorithms and applications in grass growth monitoring," Abstract and Applied Analysis, vol. 2013, Article ID 508315, 7 pages, 2013.

[7] X. Zhang, M. A. Friedl, C. B. Schaaf et al., "Monitoring vegetation phenology using MODIS," Remote Sensing of Environment, vol. 84, no. 3, pp. 471-475, 2003. 

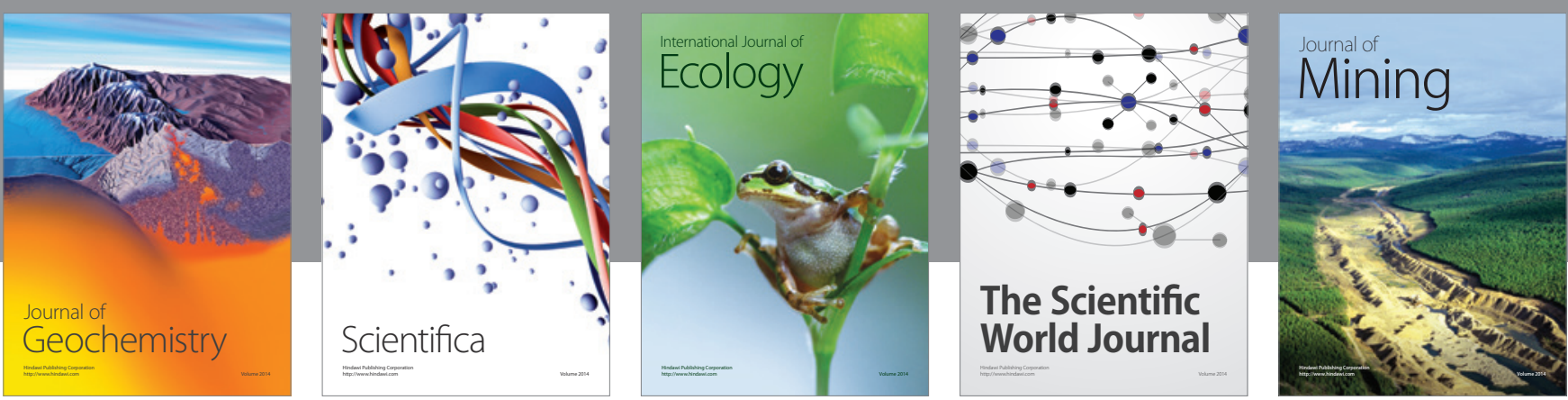

The Scientific World Journal
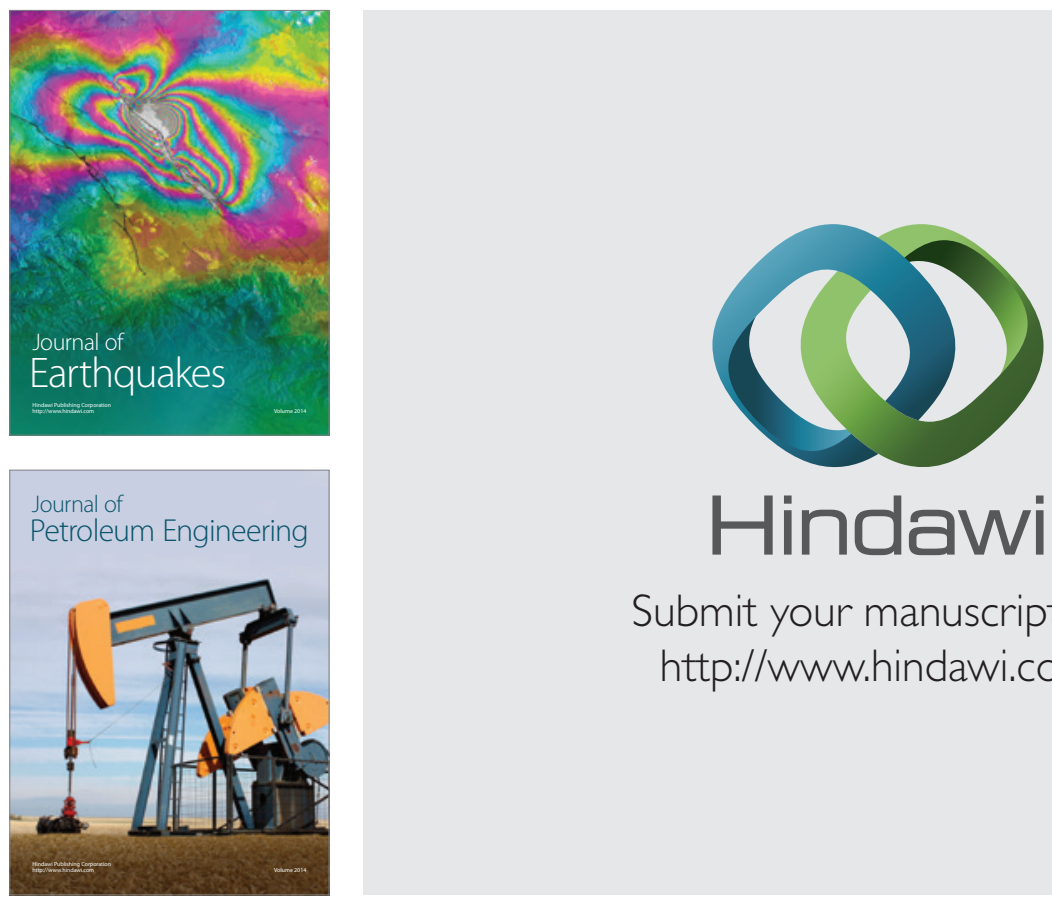

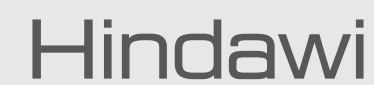

Submit your manuscripts at

http://www.hindawi.com
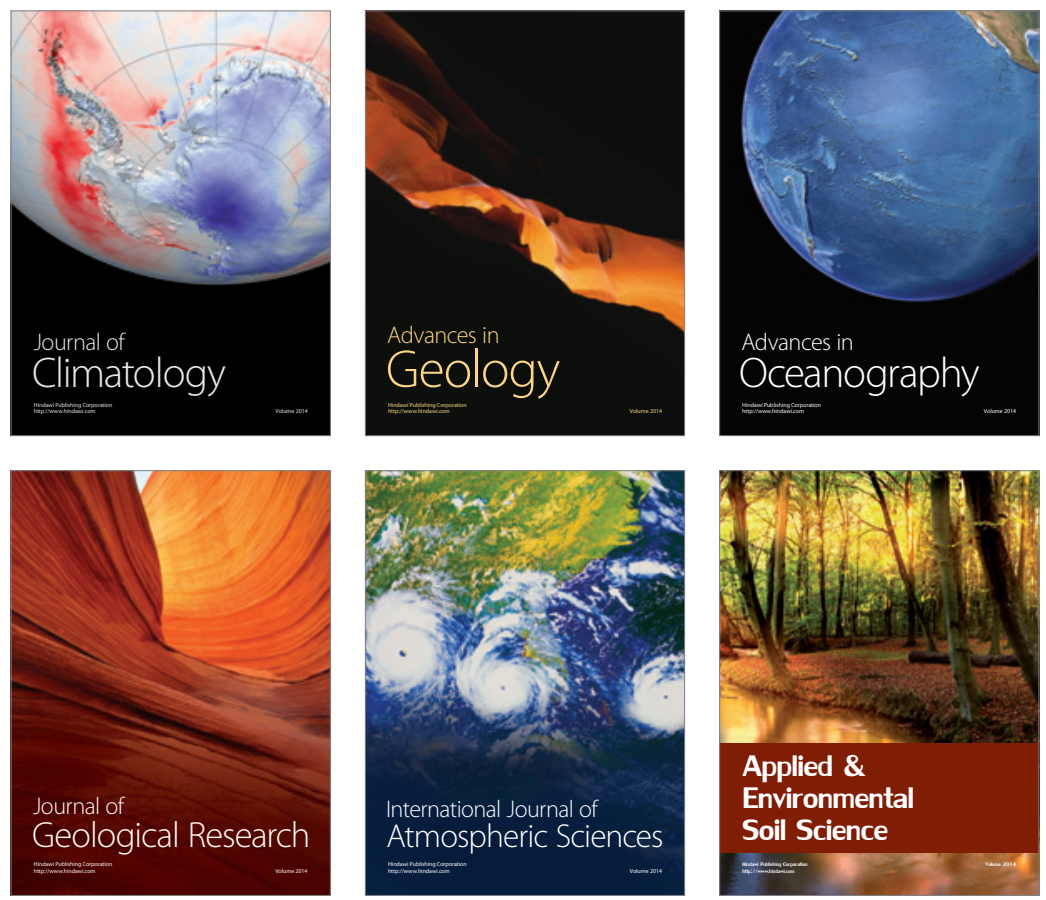
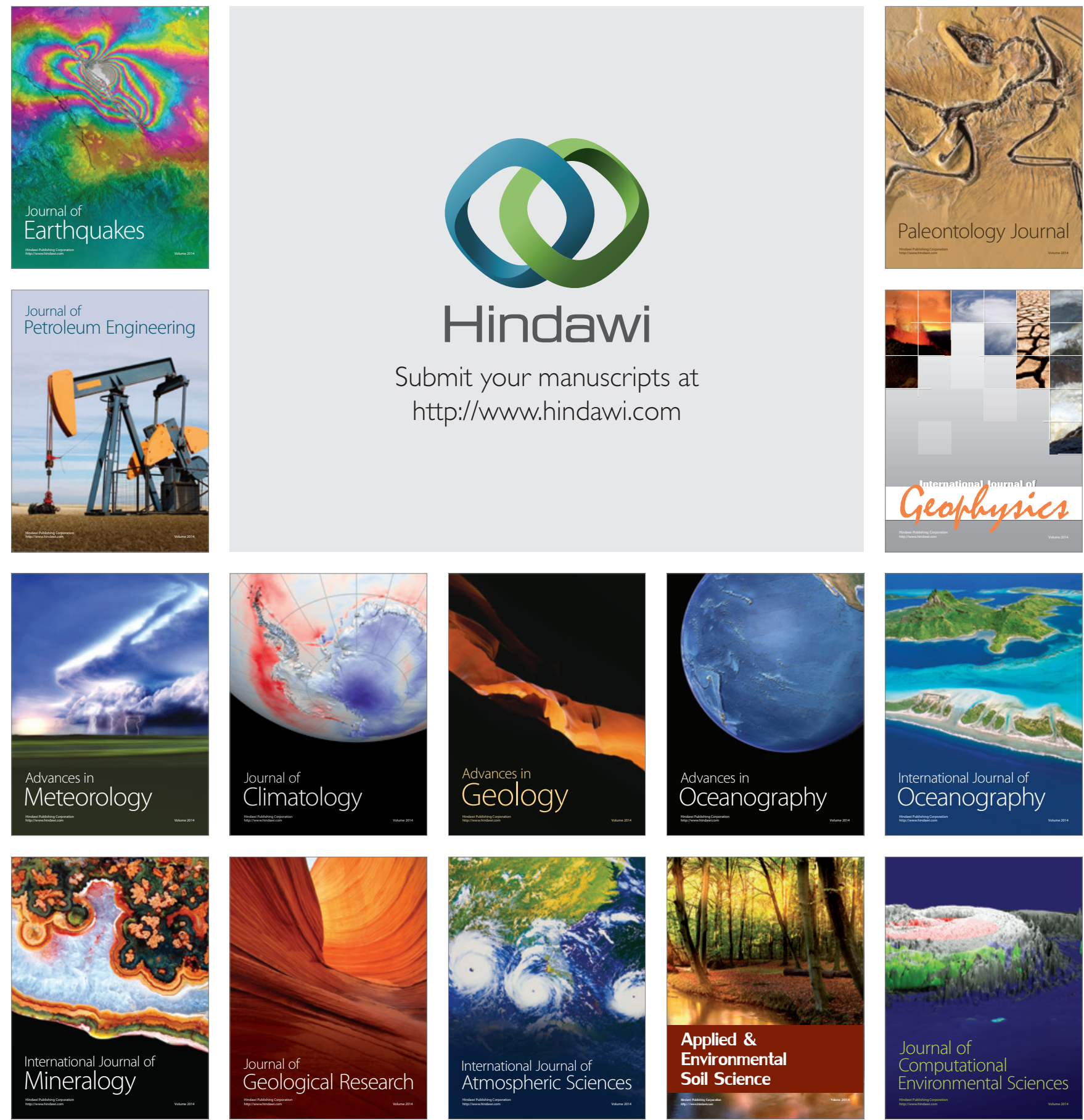